\title{
Prickly pear cactus as a raw material for lactic acid production by Lactococcus lactis subsp. lactis
}

\author{
Milouda $\underline{\text { Tamine }}^{1}$, Aicha $\underline{\text { Nancib }}^{1 *}$, Nabil $\underline{\text { Nancib }}^{1}$ and Joseph $\underline{\text { Boudrant }}^{2}$ \\ ${ }^{1}$ Laboratory of Applied Microbiology, Ferhat Abbas University, Setif 1, Algeria. \\ ${ }^{2}$ Laboratory Reactions and Process Engineering (LRPE), UMR CNRS 7224, University of Lorraine, ENSAIA, \\ Vandoeuvre Cedex, 54505, France. \\ Email: nancibaicha@yahoo.fr
}

Received 24 May 2017; Received in revised form 17 June 2017; Accepted 17 June 2017

\begin{abstract}
Aims: In recent years, microbial conversion of renewable raw materials has become an important objective in industrial biotechnology. Wastes from Opuntia ficus indica (OFI) can be considered as potential renewable raw materials in lactic acid production. In this study, the feasibility of lactic acid production using fruits and cladodes of OFI as carbohydrate feedstock was investigated.

Methodology and results: Response surface methodology (RSM) based on central composite design (CCD) was used to evaluate the effects of fermentation parameters for lactic acid production from OFI fruits by Lactococcus lactis subsp. lactis strain, isolated from Algerian raw camel milk. Acid hydrolysis of the OFI cladodes biomass was performed by dilute $\mathrm{H}_{2} \mathrm{SO}_{4}$ pretreatment. Lactic acid production from OFI fruits was analyzed using response surface methodology. Variables such as inoculum age and reducing sugars concentration were found to significantly influence lactic acid production. Final lactic acid concentration and productivity attained under optimum fermentation conditions were 32.5 $\mathrm{g} / \mathrm{L}$ and $0.74 \mathrm{~g} / \mathrm{L} . \mathrm{h}$, respectively. The cladodes of $\mathrm{OFI}$ are a potential biomass feedstock for lactic acid production. The maximum lactic acid and volumetric productivity were $16.85 \mathrm{~g} / \mathrm{L}$ and $0.65 \mathrm{~g} / \mathrm{L} . \mathrm{h}$, respectively.

Conclusion, significance and impact of study: Wastes from OFI can be a good feedstock for lactic acid production by Lactococcus lactis subsp. lactis. The methodology as a whole proved to be quite adequate for the design and optimization of the process. The experimental results also demonstrated the feasibility of using OFI cladodes hydrolysate as a substrate for lactic acid production.
\end{abstract}

Keywords: Opuntia ficus indica, acid hydrolysis, lactic acid, fermentation, response surface methodology

\section{INTRODUCTION}

Lactic acid (2-hydroxypropanoic acid), $\mathrm{CH}_{3} \mathrm{CHOHCOOH}$ is a natural organic acid with a wide range of applications in food, pharmaceutical and cosmetics industries (Sirisansaneeyakul et al., 2007; Zhang et al., 2007). It can be obtained either by the action of fermentative microorganisms or chemical synthesis. The chemical synthesis results in a racemic mixture of the two isomers $(\mathrm{D}(-)$ lactic acid and $\mathrm{L}(+)$ lactic acid), while the fermentation process can yield an optically pure form of lactic acid or racemate, depending on microorganisms, substrates and fermentation conditions employed in the production process (Zhang et al., 2007) .

The cost and availability of the substrate are the most important issues relevant to the conversion of carbohydrates to lactic acid. Application of agro-industrial wastes in bioprocesses provides an alternative way to replace the refined and costly raw materials. Hence, research efforts are focused on seeking new and effective nutritional sources and new progressive fermentation techniques, enabling the achievement of both high substrate conversion and high production (Bulut et al., 2004). Cheap raw materials, such as molasses (Umar et al., 2012), whey (Panesar et al., 2010), wheat (Gonzalez et al., 2016), date waste (Nancib et al., 2015), artichokes (Shi et al., 2012), sugarcane bagasse (Van der Pol et al., 2016) and even wood (Buyondo and Liu, 2011) have been used for lactic acid production. An alternative to these widely sources is Prickly pear cactus (Opuntia ficus indica).

Opuntia ficus indica (OFI) is a member of the Cactaceae family and is an important forage crop for livestock in many arid and semi-arid regions of the world. This plant singled out as a relevant health promoting food with a great number of potentially active nutrients, the fairly high sugar content and low acidity of the fruit makes it very susceptible to microbial invasion, thus limiting its 
storage life in the fresh state (Sepulveda and Saenz, 1990; Joubert, 1993). OFI are used for manufacturing juices, jams, jellies, pickles, candied nopales, alcoholic beverages and bioethanol (Kuloyo et al., 2014; Saenz, 2002; Retamal et al., 1987). In fact, the fruits and cladodes contain large amounts of sugars, and also contain proteins, dietary fiber, phytochemical contents, lipids, mineral elements and some vitamins (Jana, 2012; Alimi et al., 2013; Stintzing et al., 2001; Kabas et al., 2006), making its juice particularly suitable as fermentation substrates. Because of its high adaptation to the harsh desert environment and its different applications, the Opuntia ficus-indica (OFI) is an important and abundant potential raw material for the Algerian industry. Efforts are currently made to develop the fruit production and to discover new applications in the food industries. Due to the high productivity of biomass, cladodes represent a cheap and suitable substrate for the production of lactic acid. The conversion of this biomass to lactic acid usually requires some form of pre-treatment prior to hydrolysis and fermentation. The present research aimed to investigate the use of the prickly pear wastes as the main raw material for lactic acid production using Lactococcus lactis subsp. lactis. A central composite experimental design was employed in planning the experiment in order to determine which experiment variables affect lactic acid production potential from $O F I$ fruits by using RSM and a predictive polynomial quadratic equation. The ability of this strain in using dilute-acid hydrolysate of $O F /$ cladodes for lactic acid production was further tested.

\section{MATERIALS AND METHODS}

\section{Raw material}

Fruits and cladodes of OFI were harvested between July and September from the mountainous zone of Setif, East of Algeria.

\section{Extraction of $\mathrm{OFI}$ fruit sugars}

The wastes from the recovered prickly pear fruits were washed and the glochides on the peel surface were removed under running tap water by rubbing. Fruits were cut longitudinally, the flesh and thick peel were separated, and tap water added at a ratio of two parts of water to one part of fruit pulp. The mixture was heated at $50{ }^{\circ} \mathrm{C}$ for 45 min with continuous stirring followed by centrifuging at $4000 \mathrm{rpm}$ for $20 \mathrm{~min}$ in order to separate the cellulosic debris, while the supernatant was used essentially as the carbon source in the fermentation medium.

\section{Dilute acid hydrolysis of OFI cladodes}

The cladodes were washed with running water from the faucet; excess humidity was removed with absorbing paper. The cladodes were cut manually with a knife into small cubes and desiccated for $48 \mathrm{~h}$ at $60^{\circ} \mathrm{C}$ in a drying oven using cold air current. The dried samples were milled into a powdery form in an analytical grinder for a few minutes and stored at room temperature until further use. Before lactic acid fermentation, the dried cladodes were suspended in $6.8 \%$ sulfuric acid at a $10 \%(\mathrm{w} / \mathrm{v})$ loading, the mixture was heated to $100{ }^{\circ} \mathrm{C}$ for $92 \mathrm{~min}$.

\section{Detoxification of acid hydrolysate}

To eliminate inhibiting substances from the fermentation medium, the solid residue of acid hydrolysate was separated by centrifugation and the $\mathrm{pH}$ of the resulting supernatant was adjusted to 10 using $\mathrm{NaOH}$, filtering, acidifying to $\mathrm{pH} 5.5$ with sulfuric acid, and adding sodium sulfite $(1 \mathrm{~g} / \mathrm{L})$. The resulting precipitate was centrifuged off and the $\mathrm{pH}$ was adjusted to 6 .

\section{Media and growth conditions}

Lactococcus lactis subsp. lactis (Lactococcus lactis) used in this study was isolated from Algerian raw camel milk. The strain was stored in a M17 medium with $20 \%(\mathrm{v} / \mathrm{v})$ glycerol at $-20{ }^{\circ} \mathrm{C}$. The inoculum was prepared by transferring glycerol stock culture $(1 \mathrm{~mL})$ to an Erlenmeyer flask containing $100 \mathrm{~mL}$ of $\mathrm{M} 17$ medium and incubated at $33.5{ }^{\circ} \mathrm{C}$ for $6 \mathrm{~h}$ (time needed for the microorganism to reach the exponential growth phase) on a rotary shaker at $200 \mathrm{rpm}$. Then, the culture containing the production medium (OFI juice) was inoculated.

Table 1: Characteristics of raw OFI.

\begin{tabular}{lccccc}
\hline Characteristics & Water (\%) & $\begin{array}{l}\text { Protein } \\
\text { concentration (\%) }\end{array}$ & Total sugars (\%) & Reducing sugars (\%) & $\mathrm{pH}(\mathrm{units})$ \\
\hline OFl fruit & $85.25 \pm 1.39$ & $0.7 \pm 0.05$ & $15.2 \pm 0.25$ & $13.5 \pm 0.30$ & $5.5 \pm 0.07$ \\
OFl cladode & $92 \pm 1$ & $5.12^{\mathrm{a}} \pm 0.5$ & $8^{\mathrm{a}} \pm 1$ & $3.22^{\mathrm{a}} \pm 0.37$ & $5.13 \pm 0.06$ \\
\hline
\end{tabular}

OFI cladode

Values represent means \pm standard deviation calculated from three determinations

Fermentations were carried out in $250 \mathrm{~mL}$ Erlenmeyer flasks containing $100 \mathrm{~mL}$ cultivation medium. OFI juice (OFI fruit juice or OFI cladode hydrolysate) was used essentially as the carbon source in the fermentation medium. Table 1 summarizes the characteristics of the raw OFI used. The medium for the cultures has the following composition: $\mathrm{OFI}$ juice; yeast extract, $\mathrm{KH}_{2} \mathrm{PO}_{4}$ $0.5 \mathrm{~g} / \mathrm{L}, \quad \mathrm{K}_{2} \mathrm{HPO}_{4} \quad 0.5 \mathrm{~g} / \mathrm{L} ; \quad \mathrm{MnSO}_{4} \cdot \mathrm{H}_{2} \mathrm{O} \quad 0.07 \mathrm{~g} / \mathrm{L} ;$ $\mathrm{MgSO}_{4} \cdot 7 \mathrm{H}_{2} \mathrm{O} 0.5 \mathrm{~g} / \mathrm{L}$ and $\mathrm{CH}_{3} \mathrm{COONa} \cdot 3 \mathrm{H}_{2} \mathrm{O} 6 \mathrm{~g} / \mathrm{L}$ (the solution of nutrients were sterilized separately). The flasks 
were inoculated with $10 \%$ of seed inoculums and incubated at $33.5{ }^{\circ} \mathrm{C}$ on a rotary shaker at $200 \mathrm{rpm}$. The $\mathrm{pH}$ of the medium was adjusted to 6 . A central composite design (CCD) was used in the optimization of lactic acid production from OFI fruit juice. Experiments were replicated three times. All the media were sterilized at 121 ${ }^{\circ} \mathrm{C}$ for $20 \mathrm{~min}$.

Table 2: Levels of variables used in the experimental design.

\begin{tabular}{lllllll}
\hline Variables & Codes & \multicolumn{5}{c}{ Levels } \\
\cline { 3 - 7 } & & $-\alpha$ & -1 & 0 & +1 & $+\alpha$ \\
\hline Reducing sugars OFI fruit $(\mathrm{g} / \mathrm{L})$ & $X_{1}$ & 33.18 & 40 & 50 & 60 & 66.82 \\
Yeast extract $(\mathrm{g} / \mathrm{L})$ & $X_{2}$ & 6.63 & 8 & 10 & 12 & 13.36 \\
Inoculum age $(\mathrm{h})$ & $X_{3}$ & 4.63 & 6 & 8 & 10 & 11.36 \\
\hline
\end{tabular}

\section{Experimental design and statistical analysis}

The central composite design (CCD) was used to evaluate the effects of three independent variables: reducing sugars concentration of $\mathrm{OFI}$ fruit $\left(X_{1}\right)$, yeast extract concentration $\left(X_{2}\right)$ and inoculum age $\left(X_{3}\right)$. For an optimized procedure, the variables selected were prescribed into five levels, coded as $-\alpha,-1,0,+1$ and $+\alpha$, as presented in Table 2. $\alpha=1.682$

The experimental data obtained from the CCD model can be represented with the following equation:

$\mathrm{Y}_{i=\beta_{0}+} \sum_{i=1}^{k} \beta_{i} X_{i}+\sum_{i=1}^{k} \beta_{i i} X_{i}^{2}+\sum_{i=1}^{k} \beta_{i j} X_{i} X_{j}$ [Eq1]

Where $Y i$ is the predicted response, $X_{i}$ and $X_{j}$ are the independent variables in the model, $k$ is the number of independent variables, $\beta o$ is the intercept (constants and regression coefficients of the model), $\beta i$ is the linear coefficient, $\beta i i$ is the quadratic coefficient and $\beta i j$ is the interaction coefficient. Multivariate regression analysis with model equation 1 (Eq. 1) was carried out on the data to yield equation 2 (Eq. 2) which was used to optimize the product responses.

$\boldsymbol{Y}=\boldsymbol{\beta}_{0}+\boldsymbol{\beta}_{1} X_{\mathbf{1}}+\boldsymbol{\beta}_{2} X_{\mathbf{2}}+\boldsymbol{\beta}_{3} X_{\mathbf{3}}+\beta_{11} X_{1}{ }^{2}+\boldsymbol{\beta}_{22} X_{\mathbf{2}}{ }^{2}+\boldsymbol{\beta}_{33} X_{3}{ }^{2}+$ $\beta_{12} X_{1} X_{2}+\beta_{13} X_{1} X_{3}+\beta_{23} X_{2} X_{3} \quad$ [Eq. 2]

The graphical representation of these equations are called response surfaces, which was used to describe the individual and cumulative effects of the test variables on the response and to determine the mutual interactions between the test variables and their subsequent effect on the response. The probability values $(P$-values $)$ indicate the significance of each of the coefficient, which in turn governs the patterns of interactions between the variables. The quality of fit of the second-order equation was expressed by the coefficient of determination $R^{2}$, and its statistical significance was determined by the F-test. The coefficients of the equation were determined by employing MINITAB 16 software (Minitab Inc, State College, PA - www.minitab.com) and the analysis of variance (ANOVA) test was performed to assay the statistical significance of the analysis.

\section{Analytical methods}

The total sugars in $O F I$ juice were determined by the phenol-sulfuric method (Dubois et al., 1956) and reducing sugars content were determined by the colorimetric method using the UVVis spectrophotometer, (Spectronic Genesis 20) at $540 \mathrm{~nm}$ using 3,5-dinitrosalicylic acid (DNS reagent) with glucose as standard (Miller, 1959).
Glucose was measured using an enzymatic kit (Glucose PAP SL, Elitech). The protein concentrations were determined using the Lowry method with bovine serum albumin as the standard (Lowry et al., 1951). The moisture content of the raw OFI was estimated according to the AOAC method (2000). Cell growth was monitored spectrophotometrically (Spectronic 20 Genesys) by optical density (OD) measurements at $650 \mathrm{~nm}$, and lactic acid estimation was determined following Taylor method (Taylor, 1996).

\section{RESULTS AND DISCUSSION}

\section{Lactic acid production from $O F I$ fruit}

\section{Optimization of the culture conditions}

Table 3 shows the predicted lactic acid value obtained from central composite design with corresponding values observed. The polynomial model for lactic acid concentration is shown below:

$Y(\mathrm{~g} / \mathrm{L})=29.98+2.01 X_{1}+1.16 X_{2}+2.56 X_{3}-2 X_{1}^{2}-$ $2.29 X_{2}^{2}-1.8 X_{3}^{2}+0.19 X_{1} X_{2}+1.39 X_{1} X_{3}+1.53 X_{2} X_{3}$ [Eq. 3]

The fit validity of the model was checked using the determination coefficient $\left(R^{2}\right)$. The values of the determination coefficients, $R^{2}$ and adjusted $R^{2}$ which measure the model fitting reliability, were calculated and obtained as 0.91 and 0.82 , respectively. This suggests that approximately $91 \%$ of the variance is attributed to the variables, which indicate the high significance of the model, where only $9 \%$ of the total variations cannot be explained by the model. Confirmation of the adequacy of the regression model was reflected also by the good agreement between the experimental and the predicted values of the response variables as shown in Table 3 , where the experimental lactic acid concentration ranged from 19.49 to $32.42 \mathrm{~g} / \mathrm{L}$ and the corresponding predicted values were 20.13 and $29.98 \mathrm{~g} / \mathrm{L}$, respectively.

Pareto chart was used in this work for easier visualization of the main and interaction effects of the 
Table 3: Central composite design matrix showing real values along with experimental and predicted values of lactic acid concentration.

\begin{tabular}{|c|c|c|c|c|c|}
\hline \multirow[b]{2}{*}{ Run } & \multirow{2}{*}{$\begin{array}{l}\text { Reducing sugars }(\mathrm{g} / \mathrm{L}) \\
X_{1}\end{array}$} & \multirow{2}{*}{$\begin{array}{l}\text { Yeast extract }(\mathrm{g} / \mathrm{L}) \\
X_{2}\end{array}$} & \multirow{2}{*}{$\begin{array}{l}\text { Inoculum age (h) } \\
X_{3}\end{array}$} & \multicolumn{2}{|c|}{ Lactic acid concentration ( $\mathrm{g} / \mathrm{L}$} \\
\hline & & & & Experimental & Predicted \\
\hline 1 & 60 & 12 & 10 & 31.87 & 32.73 \\
\hline 2 & 50 & 13.36 & 8 & 26.64 & 25.45 \\
\hline 3 & 66.82 & 10 & 8 & 29.94 & 27.7 \\
\hline 4 & 50 & 10 & 8 & 31.59 & 29.98 \\
\hline 5 & 60 & 12 & 6 & 20.04 & 21.75 \\
\hline 6 & 50 & 10 & 11.36 & 29.39 & 29.19 \\
\hline 7 & 40 & 12 & 10 & 25.54 & 25.54 \\
\hline 8 & 50 & 10 & 8 & 29.12 & 29.98 \\
\hline 9 & 40 & 12 & 6 & 19.49 & 20.13 \\
\hline 10 & 60 & 8 & 10 & 26.09 & 26.97 \\
\hline 11 & 50 & 10 & 8 & 28.43 & 29.98 \\
\hline 12 & 50 & 10 & 8 & 27.74 & 29.98 \\
\hline 13 & 50 & 6.63 & 8 & 22.52 & 21.54 \\
\hline 14 & 60 & 8 & 6 & 20.59 & 22.11 \\
\hline 15 & 40 & 8 & 10 & 20.73 & 20.54 \\
\hline 16 & 40 & 8 & 6 & 20.59 & 21.25 \\
\hline 17 & 50 & 10 & 8 & 32.42 & 29.98 \\
\hline 18 & 50 & 10 & 4.63 & 22.52 & 20.55 \\
\hline 19 & 50 & 10 & 8 & 30.22 & 29.98 \\
\hline 20 & 33.18 & 10 & 8 & 20.87 & 20.93 \\
\hline
\end{tabular}

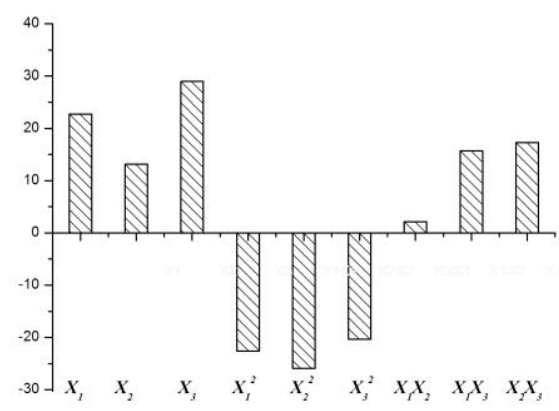

Figure 1: Pareto chart showing the effects of different independent variables on lactic acid concentration

factors to the response variable, that is, lactic acid concentration (Figure 1).

The model identified that within the studied range of experiments the inoculum age $\left(X_{3}\right)$ has the highest positive impact on the fermentation process followed by the reducing sugars $\left(X_{1}\right)$, interactive effect of yeast extract concentration and inoculum age $\left(X_{2} X_{3}\right)$, interactive effect of reducing sugars concentration and inoculum age $\left(X_{1} X_{3}\right)$, interactive effect of reducing sugars concentration and yeast extract concentration $\left(X_{1} X_{2}\right)$, in a decreasing order. While the yeast extract has a slight positive impact on the lactic acid concentration, its quadratic effect $\left(X_{2}^{2}\right)$ has the highest negative impact on the fermentation process, followed by the negative quadratic effect of reducing sugars concentration $\left(X_{1}{ }^{2}\right)$ and inoculum age $\left(X_{3}^{2}\right)$.

As shown in Table 4, a model F-value of 10.87 and a probability value of 0.000 imply significant model fit. The Lack of Fit $F$-value of 1.13 implies that there is insignificant lack of fit. The $P$-value of 0.447 for lack of fit implies that there is only $44.7 \%$ chance that the Lack of Fit $F$-value could occur due to noise. From the $P$-values of each model term (Table 4), it can be concluded that, the quadratic coefficients $\left(X_{1}{ }^{2}, X_{2}{ }^{2}\right.$ and $\left.X_{3}{ }^{2}\right)$ and linear 
coefficients $\left(X_{1}\right.$ and $\left.X_{3}\right)$ are the most significant coefficient $(p<0.01)$. The optimum level of each variable and the effect of their interactions on lactic acid production as a function of two variables were studied by plotting threedimensional response surface curves (while keeping the other variables at central point). Graphical representation of response surfaces shown in Figures 2A-2C aided the visualization of the effects of the different variables on lactic acid production. The interactive effect of reducing sugars OFI fruit concentration and yeast extract concentration on lactic acid production at a constant inoculum age of $8 \mathrm{~h}$ is shown in Figure 2A. An increase in the reducing sugars with yeast extract concentration up to the optimum point (near of the central levels) increased the lactic acid to a maximum level and a further increase in the reducing sugars OFI fruit with yeast extract concentration caused the trend to be reversed. The effect of reducing sugars OFI fruit and inoculum age on the lactic acid production is presented in Figure 2B. An increase in reducing sugars $O F I$ fruit with an increase in inoculum age resulted in an increase in lactic acid concentration. The optimal range for lactic acid production was from 45 to $50 \mathrm{~g} / \mathrm{L}$ of reducing sugars OFI fruit and from 6 to $6.8 \mathrm{~h}$ of inoculum age. Figure $2 \mathrm{C}$ shows the effect of yeast extract concentration and inoculum age on lactic acid production. The trend observed indicates that lactic acid production was favored at high inoculum age with yeast extract near the central level.

Table 4: ANOVA for response surface quadratic model obtained from experimental designs.

\begin{tabular}{llllll}
\hline Source & Degree of freedom & Sum of squares & Mean Squares & $F$-Value & $P$-Value $(P>F)$ \\
\hline Model & 9 & 349.41 & 38.82 & 10.87 & 0.000 \\
$X_{1}$ & 1 & 55.35 & 55.35 & 15.50 & $0.003^{\star *}$ \\
$X_{2}$ & 1 & 18.44 & 18.44 & 5.16 & $0.046^{*}$ \\
$X_{3}$ & 1 & 90.08 & 90.08 & 25.23 & $0.001^{\star *}$ \\
$X_{1}{ }^{2}$ & 1 & 39.01 & 57.68 & 16.15 & $0.002^{\star *}$ \\
$X_{2}{ }^{2}$ & 1 & 64.99 & 75.73 & 21.21 & $0.001^{\star *}$ \\
$X_{3}$ & 1 & 47.02 & 47.02 & 13.17 & $0.005^{\star *}$ \\
$X_{1} X_{2}$ & 1 & 0.29 & 0.28 & 0.08 & 0.782 \\
$X_{1} X_{3}$ & 1 & 15.51 & 15.51 & 4.34 & $0.064^{*}$ \\
$X_{2} X_{3}$ & 1 & 18.72 & 18.72 & 5.24 & $0.045^{*}$ \\
Residual Error & 10 & 35.71 & 3.57 & & 0.447 \\
Lack of fit & 5 & 18.97 & 3.79 & 1.13 & 0.47 \\
Pure Error & 5 & 16.74 & 3.35 & & \\
Total & 19 & 385.12 & & & \\
\hline
\end{tabular}

** Significant at $1 \%$ level

* Significant at $5 \%$ level
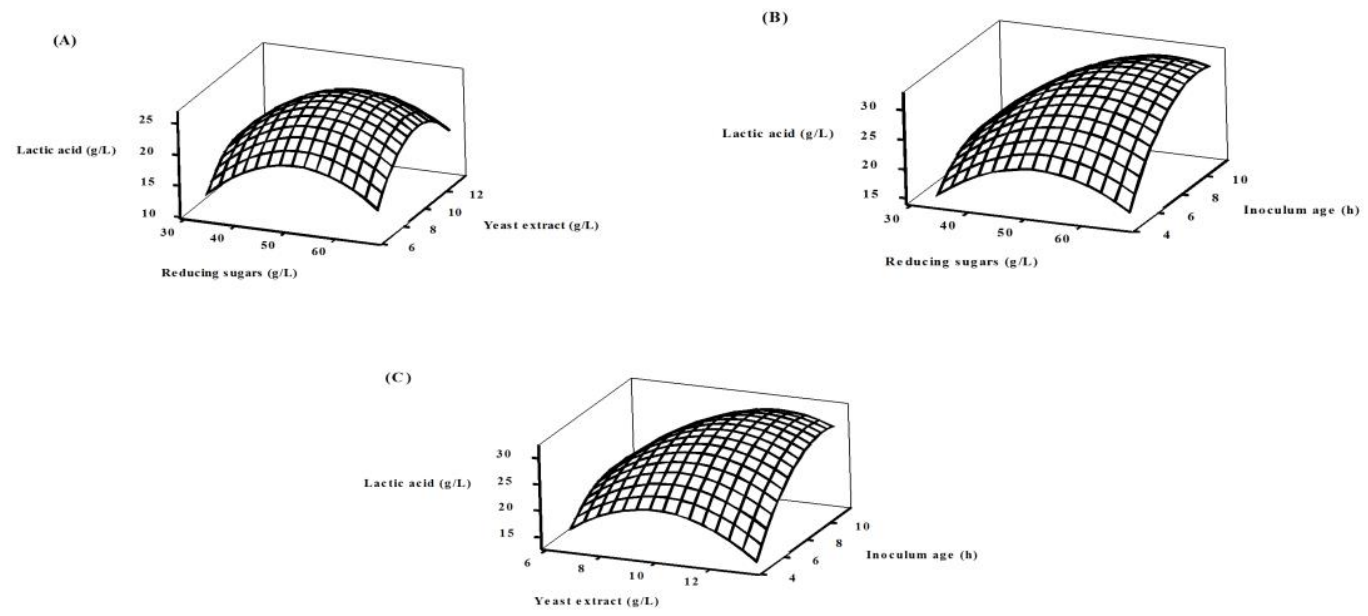

Figure 2: Three-dimensional surface plots showing the effect of different variables on lactic acid production (A) Effect of reducing sugars OFI fruit and yeast extract (B) Effect of reducing sugars OFI fruit and inoculum age (C) Effect of yeast extract and inoculums age. 


\section{Validation of the model}

To evaluate the validity of the quadratic model, the optimal medium conditions, namely, $60 \mathrm{~g} / \mathrm{L}$ initial reducing $O F I$ fruit juice sugars, $11 \mathrm{~g} / \mathrm{L}$ yeast extract and $10 \mathrm{~h}$ inoculum age were used. The profile of growth, lactic acid production, and fruit OFI sugar utilization is shown in Figure 3. Consequently, as shown in this figure, the consumption of $O F I$ fruit juice sugars increased with time of fermentation, and about $60 \%$ was consumed at the end of fermentation. Maximum yield, ([P]/[S consumed]), was obtained as $96 \%$ and the productivity equal to $0.74 \mathrm{~g} / \mathrm{L}$.h. The maximum production of lactic acid obtained was 32.5 $\mathrm{g} / \mathrm{L}$, which is in good agreement with the predicted value (33 $\mathrm{g} / \mathrm{L})$, thus confirming the model's authenticity.

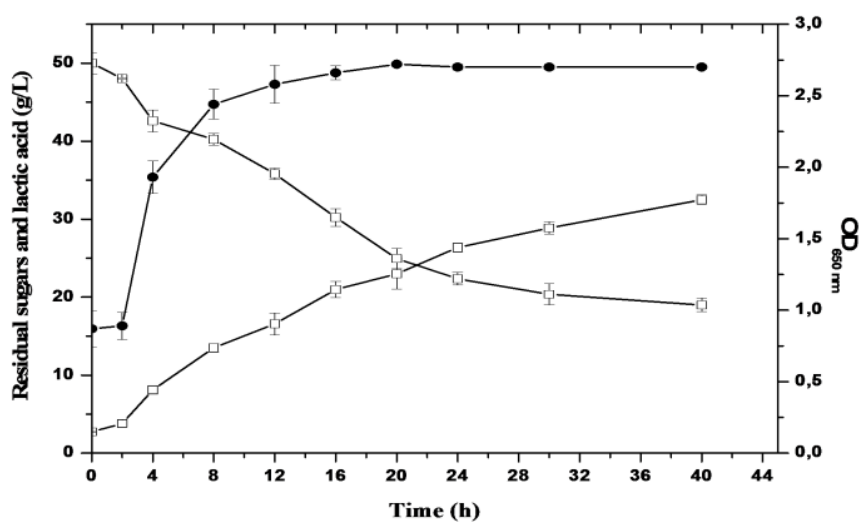

Figure 3: Kinetics of growth $(\bullet)$, sugars consumption $(\boldsymbol{\Delta})$, and lactic acid production $(\square)$ by Lactococcus lactis subsp. lactis at optimized conditions. Error bars indicate the standard deviations from three independent experiments

Note that with the initial used medium OFI fruit juice as a carbon source without supplementation), hence not optimized (data not shown), the obtained lactic acid concentration was $11.87 \mathrm{~g} / \mathrm{L}$ with lactic acid yield and a productivity of $0.5 \mathrm{~g} / \mathrm{g}$ and $0.4 \mathrm{~g} / \mathrm{L} . \mathrm{h}$, respectively.

These results also confirm the importance of prickly pear fruit juice as a potential carbon source for the production of lactic acid.

A similar result was also obtained in a study by Serna Cock and Rodriguez de Stouvenel (2006) using Lactococcus lactis subsp. lactis for lactic acid production from sugar cane molasses. A maximum lactic acid concentration of $35 \mathrm{~g} / \mathrm{L}$ was obtained. In another study by Flores-Albino et al. (2012), it was reported that the maximum lactic acid production was $19.5 \mathrm{~g} / \mathrm{L}$ using a strain of Lactobacillus sp. B2. Srivastava et al. (2015) obtained with cane molasses a maximum concentration of $55.89 \mathrm{~g} / \mathrm{L}$ using Lactobacillus delbrueckii NCIM 2025. Coelho et al. (2010) reported that the cassava wastewater for the production of lactic acid by Lactobacillus rhamnosus B 103 produceds lactic acid of $41.65 \mathrm{~g} / \mathrm{L}$ after $48 \mathrm{~h}$ of fermentation. John et al. (2008) reported $40 \mathrm{~g} / \mathrm{L}$ lactic acid production with a productivity of $0.42 \mathrm{~g} / \mathrm{L} . \mathrm{h}$ from cassava bagasse via genetically modified Lactobacillus delbrueckii. Nancib et al. (2005) reported $24.8 \mathrm{~g} / \mathrm{L}$ of lactic acid. These last authors utilized date juice as carbon source (50 $\mathrm{g} / \mathrm{L}$ of glucose) and yeast extract (10 $\mathrm{g} / \mathrm{L})$ as nitrogen source for lactic acid production with Lactobacillus casei subsp. rhamnosus NRRL-B445. During their experiments which were performed in flasks containing date palm waste, maximum concentration of lactic acid with volumetric productivity of $0.62 \mathrm{~g} / \mathrm{L}$.h was attained in $40 \mathrm{~h}$. Meziane et al. (2013) reported a maximal lactic acid concentration of $15.8 \mathrm{~g} / \mathrm{L}$ on molasses using Lactococcus lactis ssp. and in this latter case, with a much lower yield and productivity $(0.10 \mathrm{~g} / \mathrm{g}$ and $0.11 \mathrm{~g} / \mathrm{L} . \mathrm{h}$, respectively) compared to our results $(0.96 \mathrm{~g} / \mathrm{g}$ and 0.74 g/L.h).

\section{Lactic acid production from OFI cladodes hydrolysate}

Since Lactococcus lactis could not directly utilize lignocellulose, hydrolysis of $O F I$ cladodes by acid treatment was necessary to transform lignocellulosic biomass into fermentable sugars. To determine the optimal condition for hydrolysis, central composite design was applied to investigate the influence of acid concentration and treatment time of OFI cladodes on the production of fermentable sugars. The best results were obtained with acid treatment using $6.8 \%$ sulfuric acid for 92.4 min (data not shown).

The obstacle for the use of lignocellulosic hydrolysates is the inhibition effect of toxic compounds released during acid hydrolysis process. In addition to the fermentable 
sugars, compounds that are toxic to fermentative organisms such as furfural and 5-hydroxymethylfurfural were also produced in this process (Neureiter et al., 2004).

To understand the performance of Lactococcus lactis in the OFI cladodes acid hydrolysate, the latter was used as a raw material for lactic acid production. In all cases, the initial glucose level of hydrolysate was $12 \mathrm{~g} / \mathrm{L}$. The experimental results are shown in Table 5. The data shows that Lactococcus lactis could convert the sugars in hydrolysate into lactic acid. The maximum lactic acid concentration of $6.29 \mathrm{~g} / \mathrm{L}$ was achieved at $24 \mathrm{~h}$ with lactic acid productivity of $0.26 \mathrm{~g} / \mathrm{L}$.h. On the other hand, to improve lactic acid production, hydrolysate of cladodes was detoxified and supplemented with yeast extract and salts.

Table 5: Kinetics patarmeters of lactic acid production on $O F /$ juice.

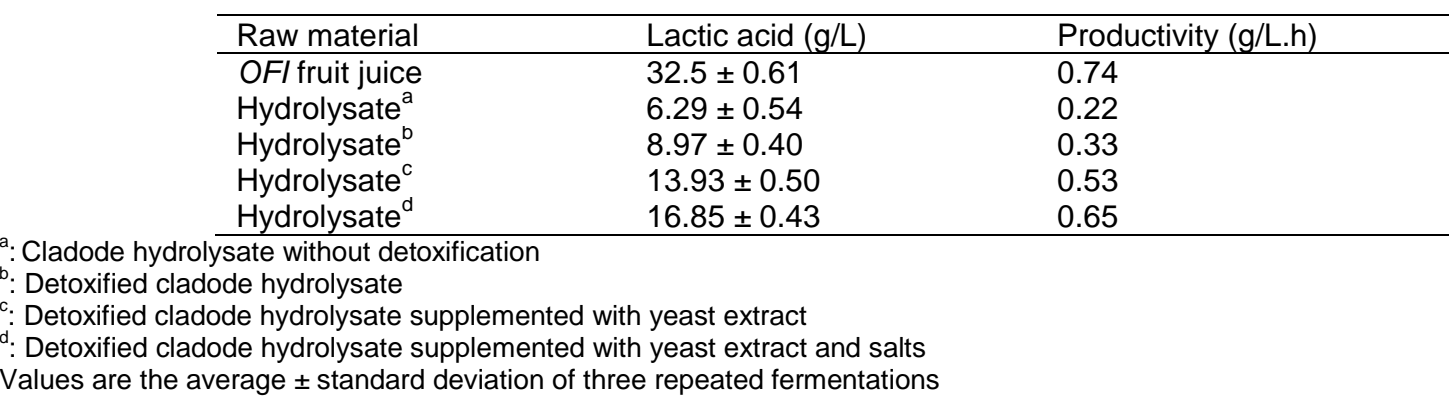

The use of the detoxified acid hydrolysate increased the lactic acid production by $42.6 \%$. Furthermore, supplementation of detoxified acid hydrolysate with $5 \mathrm{~g} / \mathrm{L}$ yeast extract and salts could notably enhance the titer of lactic acid. As can be seen in Table 5, the lactic acid production and productivity were practically threefold higher than that obtained in un-detoxified acid hydrolysate without any supplementation.

It is clear that supplementation with yeast extract and salts gave better results. Lactic acid bacteria (LAB) are known as fastidious micro organisms that cannot grow on simple mineral media supplemented only with a carbon source (Hébert et al., 2004). In addition to carbohydrates, culture media of LAB are usually supplemented with various free amino acids, peptides, nucleic acid derivatives, minerals and vitamins (John et al., 2007). The growth factors are usually provided by nitrogen sources. In particular, yeast extract has the greatest effect due to the presence of purines, pyrimidine and vitamins $B$ (Hujanen et al., 2001 ; Narayanan et al., 2004; Nancib et al., 2005; Yu et al., 2008). Indeed, these results show a high lactic concentration in comparison to other previously published studies which mention lower maximum lactic acid concentrations: $10.9 \mathrm{~g} / \mathrm{L}$ from sugarcane bagasses using Lactococcus lactis IO-1 obtained by Laopaiboon et al. (2010), $10.6 \mathrm{~g} / \mathrm{L}$ from sugarcane bagasses using Lactococcus lactis TISTER-1401 obtained by Jonglertjunya et al. (2012) and about $9 \mathrm{~g} / \mathrm{L}$ from wheatstraw hemicellulose hydrolysates with mixed culture of Lactobacillus brevis and L. pentosus obtained by Garde et al. (2002).

This high lactic acid concentration was probably related to the composition of cladodes (in sugars, vitamins, fatty acids and amino acids) and to the capacity of Lactococcus lactis to metabolize several sugars. Most bacteria have the ability to use a great variety of carbon sources as an evolutionary advantage to be able to adapt to their ever-changing habitats. Acid cladode hydrolysate contain not only hexoses but also pentoses (Akanni et al., 2014). Hexoses can easily be fermented by LAB, but a few LAB metabolize pentose sugars via the phosphoketolase pathway. Tanaka et al. (2002) reported that Lactococcus lactis could utilize xylose with a high lactate yield and low acetate production. Passerini et al. (2013) investigated the role and adaptation of Lactococcus lactis (A12) in sourdough. These authors showed that this strain was able to grow on galactose and $\mathrm{L}$-arabinose. Based on the experimental results of this study, the OFI cladodes seemed promising as a lignocellulosic biomass feedstock for lactic acid production.

\section{CONCLUSION}

Prickly pear cactus has been revealed as a suitable substrate to lactic acid production by Lactococcus lactis. The central composite design and response surface methodology enable the determination of optimal operating conditions suitable for obtaining greater lactic acid production. The validity of the model was proved by fitting the values of the variables in the second order polynomial equation and by actually carrying out the experiment at those predicted values for the three independent variables. Cladodes were also proven to be an economically feasible raw material for lactic acid production.

\section{REFERENCES}

Akanni, G. B., du Preez, J. C., Steyn, L. and Kilian, G. C. (2014). Protein enrichment of an Opuntia ficusindica cladode hydrolysate by cultivation of Candida utilis and Kluyveromyces marxianus. Journal of the Science of Food and Agriculture 95, 1094-1102. 
Alimi, H., Hfaeidha, N., Bouonia, Z., Saklyb, M. and Ben Rhoumab, K. (2013). Ameliorative effect of Opuntia ficus indica juice on ethanol-induced oxidative stress in rat erythrocytes. Experimental and Toxicologic Pathology 65, 391-396.

AOAC (2000). Official Methods of Analysis, 17th Edn. Association of Official Analytical Chemists, Gaithersburg, USA. Broihier, K. (1999). The Phytochemical Renaissance. Food Processing 44, 46-48.

Bulut, S., Elibol, M. and Ozer, D. (2004). Effect of different carbon sources on $\mathrm{L}(+)$-lactic acid production by Rhizopus oryzae. Biochemical Engineering Journal 21(1), 33-37.

Buyondo, J. P. and Liu, S. (2011). Lactic acid production by Lactobacillus pentosus from wood extract hydrolysates. Journal of Science and Technology for Forest Products and Processes 1, 38-47.

Coelho, L. F., de Lima, C. J. B., Bernardo, M. P., Alvarez, G. M. and Contiero, J. (2010). Improvement of $L(+)$-lactic acid production from cassava wastewater by Lactobacillus rhamnosus B 103. Journal of the Science of Food and Agriculture 90, 1944-1950.

Dubois, M., Gilles, K. A., Hamilton, J. K., Rebers, P. A. and Smith, F. (1956). Colorimetric method for determination of sugars and related substances. Analytical Chemistry 28, 350-356.

Flores-Albino, B., Arias, L., Gomez, J., Castillo, A., Gimeno, M. and Shirai, K. (2012). Chitin and L(+)lactic acid production from crab (Callinectes bellicosus) wastes by fermentation of Lactobacillus sp. B2 using sugar cane molasses as carbon source. Bioprocess and Biosystems Engineering 35, 11931200.

Garde, A., Jonson, G., Schmidt, A. S. and Ahring, B. K. (2002). Lactic acid production from wheat straw hemicellulose hydrolysate by Lactobacillus pentosus and Lactobacillus brevis. Bioresource Technology 81, 217-223.

Gonzalez, K., Tebbani, S., Lopes, F., Thorigné, A., Givry, S., Dumur, D. and Pareau, D. (2016). Modelling the continuous lactic acid production process from wheat flour. Applied Microbiology and Biotechnology 100, 147-159.

Hébert, E. M., Raya, R. R. and Giori, G. S. (2004). Nutritional requirements of Lactobacillus delbrueckii subsp. lactis in a chemically defined medium. Current Microbiology 49, 341-345.

Hujanen, M., Linko, S., Linko, Y. and Leisola, M. (2001). Optimisation of media and cultivation conditions for $\mathrm{L}(+)(\mathrm{S})$-lactic acid production by Lactobacillus casei NRRLB-441. Applied Microbiology and Biotechnology 56, 126-130.

Jana, S. (2012). Nutraceutical and functional properties of cactus pear (Opuntia spp.) and its utilization for food applications. Journal of Engineering Research and Studies 3, 60-66.

John, R. P., Gangadharan, D. and Nampoothiri, K. M. (2008). Genome shuffling of Lactobacillus delbrueckii mutant and Bacillus amyloliquefaciens through protoplasmic fusion for L-lactic acid production from starchy wastes. Bioresource Technology 99, 80088015.

John, R. P., Nampoothiri, K. M. and Pandey, A. (2007). Fermentative production of lactic acid from biomass: An over-view on process developments and future perspectives. Applied Microbiology and Biotechnology 74, 524-534.

Jonglertjunya, W., Pranrawang, N., Phookongka, N., Sridangtip, T., Sawedrungreang, W. and Krongtaew, C. (2012). Utilization of sugarcane bagasse for lactic acid production by acid hydrolysis and fermentation using Lactobacillus sp. World Academy of Science, Engineering and Technology 66, 173-178.

Joubert, E. (1993). Processing of the fruit of five prickly pear cultivars grown in South Africa. International Journal of Food Science and Technology 28, 377-387.

Kabas, O., Ozmerzi, A. and Akinci, I. (2006). Physical properties of cactus pear (Opuntia ficus india L.) grown wild in Turkey. Journal of Food Engineering 73, 198202.

Kuloyo, O. O., du Preez, J. C., García-Aparicio Mdel, P., Kilian, S. G., Steyn, L. and Görgens, J. (2014). Opuntia ficus indica cladodes as feedstock for ethanol production by Kluyveromyces marxianus and Saccharomyces cerevisiae. World Journal of Microbiology and Biotechnology 30, 3173-3183.

Laopaiboon, P., Thani, A., Leelavatcharamas, V. and Laopaiboon, L. (2010). Acid hydrolysis of sugarcane bagasse for lactic acid production. Bioresource Technology 101, 1036-1043.

Lowry, O. H., Rosebrough, N. J., Farr, A. L. and Randall, R. J. (1951). Protein measurement with the folin phenol reagent. Journal of Biological Chemistry 193, 265-275.

Meziane, M., Dilmi Bouras, A. and El Hameur, H. (2013). Lactic acid fermentation of a diluted molasses medium by two strains of Lactococcus lactis ssp. immobilized on pouzzolane and bone bovine conference: ISITES, At Sakarya, Turquie 774-782.

Miller, G. L. (1959). Use of dinitrosalicylic acid reagent for determination of reducing sugar. Analytical Chemistry 31, 426-428.

Nancib, A., Nancib, N., Boubendir, A. and Boudrant, J. (2015). The use of date waste for lactic acid production by a fed-batch culture using Lactobacillus casei subsp. rhamnosus. Brazilian Journal of Microbiology 46, 893-902.

Nancib, A., Nancib, N., Meziane-Cherif, D., Boubendir, A., Fick, M. and Boudrant, J. (2005). Joint effect of nitrogen sources and $B$ vitamin supplementation of date juice on lactic acid production by Lactobacillus casei subsp. rhamnosus. Bioresource Technology 96(1), 63-67.

Narayanan, N., Roychoudhury, P. K. and Srivastava, A. (2004). $L(+)$ lactic acid fermentation and its product polymerization. Electronic Journal of Biotechnology 7 , 167-179.

Neureiter, M., Danner, H., Madzingaidzo, L., Miyafuji, H., Thomasser, C., Bvochora, J., Bamusi, S. and 
Braun, R. (2004). Lignocellulose feedstocks for the production of lactic acid. Chemical and Biochemical Engineering Quarterly 18(1), 55-63.

Panesar, P. S., Kennedy, J. F., Knill, C. J. and Kosseva, M. (2010). Production of $L(+)$ lactic acid using Lactobacillus casei from whey. Brazilian Archives of Biology and Technology 53, 219-226.

Passerini, D., Coddeville, M., Le Bourgeois, P., Loubière, P., Ritzenthaler, P., Fontagné-Faucher, C., Daveran-Mingot, M. L. and Cocaign-Bousquet, M. (2013). The carbohydrate metabolism signature of Lactococcus lactis Strain A12 reveals its sourdough ecosystem origin. Applied and Environmental Microbiology 79, 5844-5852.

Retamal, N., Duran, J. M. and Fernandez, J. (1987). Ethanol production by fermentation of fruits and cladodes of prickly pear cactus (Opuntia ficus-indica (L.) Miller). Journal of the Science of Food and Agriculture 40, 213-218.

Saenz, C. (2002). Cactus pear fruit and cladodes: A source of functional components for foods. Acta Hort 581, 253-263.

Sepulveda, E. and Saenz, C. (1990). Caracteristicas quimicas y fisicas de pulpa de tuna (Opuntia ficus indica). Revista de Agroquimica y Tecnologia de Alimentos 30, 51-555.

Serna Cock, L. and Rodriguez de Stouvenel, A. (2006). Lactic acid production by a strain of Lactococcus lactis subs. lactis isolated from sugar cane plants. Electronic Journal of Biotechnology 9, 40-45.

Shi, Z., Wei, P., Zhu, X., Cai, J., Huang, L. and Xu, Z. (2012). Efficient production of I-lactic acid from hydrolysate of Jerusalem artichoke with immobilized cells of Lactococcus lactis in fibrous bed bioreactors. Enzyme and Microbial Technology 51, 263-268.

Sirisansaneeyakul, S., Luangpipat, T., Vanichsriratana, W., Srinophakun, T., Chen, H. H. and Chisti, Y. (2007). Optimization of lactic acid production by immobilized Lactococcus lactis IO-1. Journal of Industrial Microbiology and Biotechnology 34, 381-391.

Srivastava, A. K., Tripathi, A. D., Jha, A., Poonia, A. and Sharma, N. (2015). Production, optimization and characterization of lactic acid by Lactobacillus delbrueckii NCIM 2025 from utilizing agro-industrial byproduct (cane molasses). Journal of Food Science and Technology 52, 3571-3578.

Stintzing, F. C., Schieber, A. and Carle, R. (2001). Phytochemical and nutritional significance of Cactus pear. European Food Research and Technology 212, 396-407.

Tanaka, K., Komiyama, A., Sonomoto, K., Ishizaki, A., Hall, S. J. and Stanbury, P. F. (2002). Two different pathways for D-xylose metabolism and the effect of xylose concentration on the yield coefficient of $\mathrm{L}$ lactate in mixed acid fermentation by the lactic acid bacterium Lactococcus lactis 10-1. Applied Microbiology and Biotechnology 60, 160-167.
Taylor, A. C. C. K. (1996). A simple colorimetric assay for muramic acid and lactic acid. Applied Biochemistry and Biotechnology 56, 49-58.

Umar, F., Faqir, M. A., Tahir, Z., Sajjad, U. R., Mouhammd Atif, R., Anwaar, A. and Khashif, A. (2012). Optimization of lactic acid production from cheap raw material: Sugarcane molasses. Pakistan Journal of Botany 44, 333-338.

Van der Pol, E. C., Eggink, G. and Weusthuis, R. A. (2016). Production of $L(+)$-lactic acid from acid pretreated sugarcane bagasse using Bacillus coagulans DSM2314 in simultaneous saccharification and fermentation strategy. Biotechnology for Biofuels 9, 248.

Yu, L., Lei, T., Ren, X., Pei, X. and Feng, Y. (2008). Response surface optimization of $\mathrm{L}-(+)$-lactic acid production using corn steep liquor as an alternative nitrogen source by Lactobacillus rhamnosus GMCC 1466. Biochemical Engineering Journal 39, 496-502.

Zhang, Z. Y., Jin, B. and Kelly, J. M. (2007). Production of lactic acid from renewable materials by Rhizopus fungi. Biochemical Engineering Journal 35, 251-263. 